\title{
Exogenous Ethylene Precursors and Hydrogen Peroxide Aid in Early Seed Dormancy Release in Sweet Cherry
}

\author{
Michael Stein, Corina Serban, and Per McCord \\ Irrigated Agriculture Research and Extension Center, Washington State University, Prosser, WA \\ 99350
}

\begin{abstract}
Additional INDEX wORDs. germination, Prunus avium, stratification
Abstract. Seeds of sweet cherry (Prunus avium) possess a strong endodormancy response that traditionally requires months of stratification before germination can occur. Accelerating artificial dormancy release could be an important aspect of improving progress in a sweet cherry breeding program by increasing the first season growth period. In this study, seeds were exogenously treated with ethephon, 1-aminocyclopropane-1-carboxylic acid (ACC), kinetin, hydrogen peroxide, and acidified nitrite to attempt to induce germination with reduced stratification times. Findings showed that ethephon, ACC, and hydrogen peroxide all significantly increase early seed germination rates. Stratification time had the largest effect on increasing germinations, with significantly higher germination percentages accompanying increased stratification times that plateaued at 3 months of stratification. Stratification is vital for proper seedling development because plants grown from seeds with no stratification are significantly shorter and have reduced internode lengths compared with seeds with 4 weeks of stratification.
\end{abstract}

Seed dormancy, specifically endodormancy, is a strong inhibitor of rapid germination in stone fruit seeds, including those of sweet cherry (Prunus avium). Endodormancy has been suggested to be a crucial process in seeds because it prevents germination during the winter, when chances of survival are lowest (Finkelstein et al., 2008; Kermode, 2005). In breeding programs, the current method of removing endodormancy is through stratification, which involves simulating winter by keeping seeds chilled for 3 to 4 months until germination occurs naturally. To overcome this waiting period, methods to artificially remove seed dormancy have been extensively studied.

The main hormone responsible for maintaining seed dormancy is abscisic acid (ABA) (Sondheimer et al., 1968). The ABA levels decrease significantly in stone fruit seeds as the stratification time increases (Chen et al., 2007; Leida et al., 2012). Because seed dormancy is ultimately controlled by the balance between ABA and gibberellic acid (GA), a decrease in ABA would tip the hormonal balance toward GA and the allowance of germination after sufficient stratification (Finkelstein et al., 2008)

In addition to stratification, there are hormones and chemicals that have been found to counteract the effects of ABA and increase early seed germination rates. Two hormones in the ethylene pathway, ethylene and its precursor ACC, have been found to increase seed germination percentages of both apple (Malus $\times$ domestica) and grape (Vitis vinifera) when exogenously applied (Gniazdowska et al., 2010a; Selim et al., 1981). Ethylene helps to promote germination by reducing sensitivity to ABA (Finkelstein et al., 2008; Ghassemian et al., 2000). The chemical families antagonistic to $\mathrm{ABA}$ are the reactive oxygen

Received for publication 24 June 2020. Accepted for publication 8 Oct. 2020. Published online 25 November 2020.

P.M. is the corresponding author. E-mail: phmccord@wsu.edu.

This is an open access article distributed under the CC BY-NC-ND license (https://creativecommons.org/licenses/by-nc-nd/4.0/). species (ROS) and reactive nitrogen species (RNS). These reactive species have been found to reduce seed sensitivity to ABA (Gniazdowska et al., 2010a). Hydrogen peroxide, a ROS and well-known molecular signaling agent, may also promote GA biosynthesis (El-Maarouf-Bouteau and Bailly, 2008; Liu et al., 2010). Much like ACC and ethylene, ROS and RNS can work in conjunction, with RNS promoting the accumulation and function of ROS (El-Maarouf-Bouteau and Bailly, 2008; Gniazdowska et al., 2010a, 2010b; Krazuska and Gniazdowska, 2012; Liu et al., 2010). Hydrogen peroxide has also been found to upregulate genes responsible for ABA catabolism, thus reducing the levels of the inhibiting hormone in the seed (Liu et al., 2010). ROS interact with the ethylene pathway, thereby promoting ethylene responsive transcription factors and facilitating the conversion of ACC to ethylene in vitro (Gniazdowska et al., 2010a; Oracz et al., 2009). Seeds treated with both ROS and RNS have been found to emit a significantly higher amount of ethylene gas (Gniazdowska et al., 2010a).

One of the primary methods of ABA-imposed seed dormancy is the suppression of cell division. Kinetin is a member of the cytokinin hormone family that has the role of promoting cellular division (Miller et al., 1955). Kinetin is known to encourage seed germination, and exogenous applications of the hormone have been found to significantly increase germination percentages when applied in sufficient quantities (Bulard, 1985; Khan, 1971; Selim et al., 1981).

The goal of this experiment was to evaluate the effects of various treatments that have been shown to promote germination in seeds of sweet cherry. If early seed germination can be artificially induced, then a large block of time can be opened during the colder months for genetic testing, early phenotyping, and additional plant growth.

\section{Materials and Methods}

Plant material. Open-pollinated seeds $(\approx 1800$ seeds per cultivar/selection) were collected from three sweet cherry 
Table 1. Treatments used in this study to promote germination of sweet cherry. The molarity of each solution for the initial $24-\mathrm{h}$ seed soak is given along with the biological effects of each chemical.

\begin{tabular}{lcl}
\hline Treatment & Solution molarity & Effect \\
\hline Ethephon & $2 \mathrm{mM}$ & ABA sensitivity inhibition \\
ACC & $2 \mathrm{mM}$ & Ethylene precursor \\
Kinetin & $93 \mu \mathrm{M}$ & Cell division promotion \\
Hydrogen peroxide & $880 \mathrm{mM}$ & Promotes ABA catabolism, promotes GA and ethylene biosynthesis \\
Acidified nitrite & Gaseous & Promotes hydrogen peroxide accumulation \\
\hline
\end{tabular}

$\overline{\mathrm{ACC}}=$ 1-aminocyclopropane-1-carboxylic acid, ABA = abscisic acid, GA = gibberellic acid.

cultivars (Van, Hedelfingen, and Lambert) and one breeding selection [FR01T038 (a Lapins $\times$ Regina progeny)]. Mature fruit were harvested in July 2019, and they were immediately frozen at $-20^{\circ} \mathrm{C}$ for $24 \mathrm{~h}$ and then thawed to allow the flesh to be easily removed via pressurized water. The endocarp of each seed was removed by cracking it open with a pair of anvil pruners; however, the seedcoat was left on the seed to recreate conditions found during the breeding program. Seeds were surface-sterilized by soaking for $10 \mathrm{~min}$ in a 1:10 dilution of commercial chlorine bleach, followed by one to two rinses with deionized water. Seeds were stored in the dark at $2{ }^{\circ} \mathrm{C}$ for $\approx 1$ week during the process of endocarp removal.

Germination tests. A previous small-scale pilot study performed at our laboratory that involved the stratification of seeds with low germination rates showed a limited increase in germination numbers for seeds treated with ethephon, ACC, and hydrogen peroxide compared with untreated seeds. The use of GA has been successfully used to improve germination in sweet cherry (Cetinbas and Koyuncu, 2006; Fogle and McCrory, 1960; Javanmard et al., 2014). However, our use of GA during another preliminary experiment with stratified seeds did not increase germination; however, it did cause excessive elongation of seedling internodes.

Seeds from each of the four open-pollinated sources were separated into six groups of equal size. Chemical treatments (Table 1) were administered at room temperature under typical room lighting. The first group was treated as a control and submerged in water. The second group was submerged in a 0.88 -M solution of hydrogen peroxide. The third group was submerged in a $93-\mu \mathrm{M}$ kinetin solution. The fourth group was exposed to nitric oxide $\left(\mathrm{NO}^{-}\right)$via acidified nitrite created by combining $10 \mathrm{~mL}$ of $20 \mathrm{~mm} \mathrm{NaNO}{ }_{2}$ with $10 \mathrm{~mL}$ of $0.1 \mathrm{M} \mathrm{HCl}$ inside a sealed container and using methodology described by Gniazdowska et al. (2010b). The fifth group was submerged in a $2-\mathrm{mm}$ ACC solution. The sixth group was submerged in a 2-mM ethephon solution. All treatments lasted $24 \mathrm{~h}$.

After the seeds were removed from the treatment solutions, Captan fungicide was applied to further prevent future fungal growth on the seeds. The seeds for each cultivar $\times$ treatment combination were separated into groups containing between 31 and 35 seeds. The seeds were placed on paper towels and wetted with deionized water before being placed in zipper-closure plastic bags. Two bags (replicates) for each cultivar $\times$ treatment combination were placed in a growth chamber at $25^{\circ} \mathrm{C}$ under a $16-\mathrm{h} / 8$-h light/dark cycle. The remaining seeds were placed in a $2{ }^{\circ} \mathrm{C}$ cooler to begin varying lengths of stratification. Seeds in the growth chamber were checked weekly, and the numbers of germinated seeds were recorded. Germination was determined by $5-\mathrm{mm}$ emergence of either the radicle or true leaves (radicle emergence occurred first at least $90 \%$ of the time). Germinated seeds were removed from the paper towel to avoid seedling death and decomposition, and water was added to paper towels as necessary. The counting process was repeated for 4 weeks. At the end of 4 weeks, ungerminated seeds were counted and disposed. Every $30 \mathrm{~d}$, two new replicates from each treatment $\times$ cultivar combination were removed from the cooler and placed in the growth chamber.

SEEDLING PHENOTYPES. Four germinated seeds from each treatment $\times$ cultivar combination from both the unchilled and 1month stratified seeds were planted. The plants were grown in a greenhouse in a peatmoss-based growth media with supplemental lighting (16-20 h/d, cool white fluorescent lamps) and a minimum temperature of $\approx 21{ }^{\circ} \mathrm{C}$ during the fall and winter. The stratified seeds were grown for 2 months, and the nonstratified seeds were grown for 3 months. Plants were fed a complete liquid fertilizer mix containing $150 \mathrm{mg} \cdot \mathrm{L}^{-1}$ nitrogen to ensure sufficient nutrition. At the end of the growing period, plant height and leaf number were recorded, and seedling morphology was examined to determine if any of the chemical treatments had detrimental effects on the seedlings.

Statistical analysis. To compensate for different seed batch sizes, raw germination numbers were converted to percentages of seed germinated. All statistical analyses were performed based on these percentages rather than raw data. Data were analyzed using a three-way analysis of variance and R (R Foundation for Statistical Computing, Vienna, Austria); the three variables were cultivar, treatment, and stratification time. The interactions of the three independent variables were also tested. The least squared means of average germination values were calculated, and Tukey's range tests were performed to determine whether seed germination percentages for the different treatments were significantly different from those of the control and from those of each other.

\section{Results}

Germination. There were significant differences in germination percentages of different treatments and other experimental effects (Table 2). For stratification periods of 0 to 2 months, cultivar, treatment, and time were each highly significant $(P<0.0001)$, and there was a significant treatment $\times$ stratification time interaction $(P<0.001)$. For 3 and 4 months, treatment was the most highly significant $(P<0.001)$, followed by cultivar $\times$ treatment and cultivar effects $(P<0.01$ and $P<$ 0.05 , respectively). The overall effects of cultivar are shown in Fig. 1. The beneficial effects of certain treatments were only found in seeds that had 1 or 2 months of stratification (Table 3). Seeds treated with hydrogen peroxide, ACC, and ethephon had germination rates that were $80 \%$ to $153 \%$ higher than that of the control after 1 month of stratification and $30 \%$ to $56 \%$ higher 
Table 2. Probability values of the three-way analysis of variance of sweet cherry germination treatments and treatment interactions. Before analysis, the dataset was divided into two groups; 0 2 mo. of stratification, which saw limited germination, and 3-4 mo. of stratification, which had nearly complete germination.

\begin{tabular}{|c|c|c|}
\hline Effect & $\frac{\text { Stratification: } 0-2 \mathrm{mo}}{P}$ & $\frac{\text { Stratification: } 3-4 \mathrm{mo}}{P}$ \\
\hline Cultivar & $<0.0001$ & $<0.05$ \\
\hline Treatment & $<0.0001$ & $<0.001$ \\
\hline Time & $<0.0001$ & NS \\
\hline Cultivar $\times$ treatment & NS & $<0.01$ \\
\hline Cultivar $\times$ time & NS & NS \\
\hline Treatment $\times$ time & $<0.001$ & NS \\
\hline Cultivar $\times$ treatment $\times$ time & NS & NS \\
\hline
\end{tabular}

NS $=$ nonsignificant $(P>0.05)$.

Table 3. Sweet cherry germination percentages expressed as the population least squares means of each treatment. Germination numbers refer to the percentage of seeds germinated after 4 weeks in the growth chamber. Treatment percentages within a column with the same letter are not significantly different from each other based on Tukey's range test.

\begin{tabular}{lccccc}
\hline & \multicolumn{5}{c}{ Stratification period } \\
\cline { 2 - 5 } Treatment & $14.9 \mathrm{a}$ & $19.9 \mathrm{a}$ & $39.6 \mathrm{ab}$ & $95.7 \mathrm{~b}$ & $97.0 \mathrm{a}$ \\
\hline Control & $19.8 \mathrm{a}$ & $34.9 \mathrm{~b}$ & $62.4 \mathrm{~d}$ & $97.7 \mathrm{~b}$ & $98.0 \mathrm{a}$ \\
Ethephon & $20.6 \mathrm{a}$ & $31.3 \mathrm{~b}$ & $55.2 \mathrm{~d}$ & $96.8 \mathrm{~b}$ & $98.4 \mathrm{a}$ \\
ACC & $18.0 \mathrm{a}$ & $33.1 \mathrm{~b}$ & $52.1 \mathrm{~cd}$ & $89.6 \mathrm{a}$ & $91.3 \mathrm{a}$ \\
Hydrogen peroxide & $13.8 \mathrm{a}$ & $25.0 \mathrm{a}$ & $40.5 \mathrm{bc}$ & $94.5 \mathrm{ab}$ & $92.6 \mathrm{a}$ \\
Kinetin & $12.8 \mathrm{a}$ & $21.8 \mathrm{a}$ & $27.8 \mathrm{a}$ & $96.1 \mathrm{~b}$ & $97.8 \mathrm{a}$ \\
Nitric oxide & 16.7 & 27.7 & 45.1 & 95.1 & 95.9 \\
Mean & 16.7 &
\end{tabular}

$\mathrm{ACC}=1$-aminocyclopropane-1-carboxylic acid.

than that of the control after 2 months of stratification. Seeds treated with $\mathrm{NO}^{-}$and kinetin had germination levels that were not significantly different from those of the control. Treatment effects remained stable across populations because cultivar $x$ treatment interactions were not significant (Table 2). Seeds stratified for 3 and 4 months had germination rates that were consistently near or more than $90 \%$ (Table 3 ). At that point, none of the treatments had germination rates higher than that of the control. Seeds from 'Lambert' and 'Hedelfingen' trees that were treated with hydrogen peroxide germinated at a slightly lower rate than the control and all other treatments; however, there was no difference in the germination rates of 'Van' and FR01T038 seeds (data not shown). This significant (but variable) negative effect of hydrogen peroxide contributed to the significant cultivar $\times$ treatment interaction seen after 3 and 4 months of stratification.

Overall germination percentages increased markedly as stratification time increased (Table 3, Fig. 2). Unstratified seed germination percentages never increased above $20 \%$ for any treatment. This number increased to $27.7 \%$ for seeds stratified for 1 month and $45.1 \%$ for seeds stratified for 2 months. After 3 months, stratification requirements had been met and seed germination rates approached $100 \%$.

As seen in Fig. 2, temperature changes also greatly increased seed germination for stratification periods between 1 and 3 months. The majority of germinations occurred during the first week after removal from the cold. For seeds stratified for 1 month, $71 \%$ of germinations occurred during this first week.
Seeds stratified for 2 months resulted in $77 \%$ experiencing germinations during the first week. Seeds stratified for 3 months, despite experiencing a large number of germinations while still undergoing stratification, resulted in 54\% experiencing germination during the first week after removal from the cold. After 4 months of stratification, germination rates exceeded $90 \%$ while seeds were still in the cooler.

Phenotypic effects. Plants that grew from seeds that underwent 1 month of stratification were significantly taller $(P<0.0001)$ than unchilled plants. Stratification led to an average increase of $45 \mathrm{~mm}$, thus increasing plant heights by almost 50\% (Fig. 3). There were no differences in height between different families or different treatments, and the family $\times$ month and treatment $\times$ month interactions were not significant. Regarding leaf number, there was no significant difference between stratified and unchilled seeds, nor was there any difference between families or treatments.

\section{Discussion}

We have determined that it is possible to significantly increase sweet cherry seed germination rates artificially by using ethylene pathway hormones and ROS (Table 3). The presence of a seedcoat has a highly significant effect on delaying seed germination (Kim, 2019; Martinez-Gomez and Dicenta, 2001). The seedcoat of stone fruits is known to contain a larger amount of ABA and containing far higher levels of the hormone than other structures including the embryo (Piaggesi et al., 1991). Because the seedcoat was the structure in contact with the treatment solution, the antagonistic reaction of the treatments with ABA located within the integument likely helped to increase germination rates. Javanmard et al. (2014) demonstrated increased germination of 'Lambert' sweet cherry seeds by washing the seeds, which helped to remove or dilute $\mathrm{ABA}$ in the seedcoat, as well as by soaking the seeds in GA, which is an ABA antagonist. The failure of the RNS to increase germination rates is likely due to the poor performance of the gaseous acidified nitrate when producing NO in the seeds. Soaking the seeds in an aqueous solution using another NO donor, sodium nitroprusside, may yield results similar to those of successful NO treatments (Gniazdowska et al., 2010a, 2010b; Krazuska and Gniazdowska, 2012).

In our experiment, kinetin did not achieve an increased level of germination like that seen by Selim et al. (1981) and Bulard (1985). Aside from the fact that these earlier reports dealt with different genera (Vitis and Malus, respectively), our results may have differed because of the different modes of action between kinetin and the other treatments. Unlike ABA antagonists, the artificial addition of kinetin should break dormancy by promoting cell division that had been repressed by ABA. Because removing the seedcoat, as was performed by Bulard (1985), was required to achieve high germination levels, it may indicate that kinetin alone cannot overcome the large amounts of ABA present. It is also possible that the kinetin levels used in our study were too high. Bulard (1985) noted that concentrations 

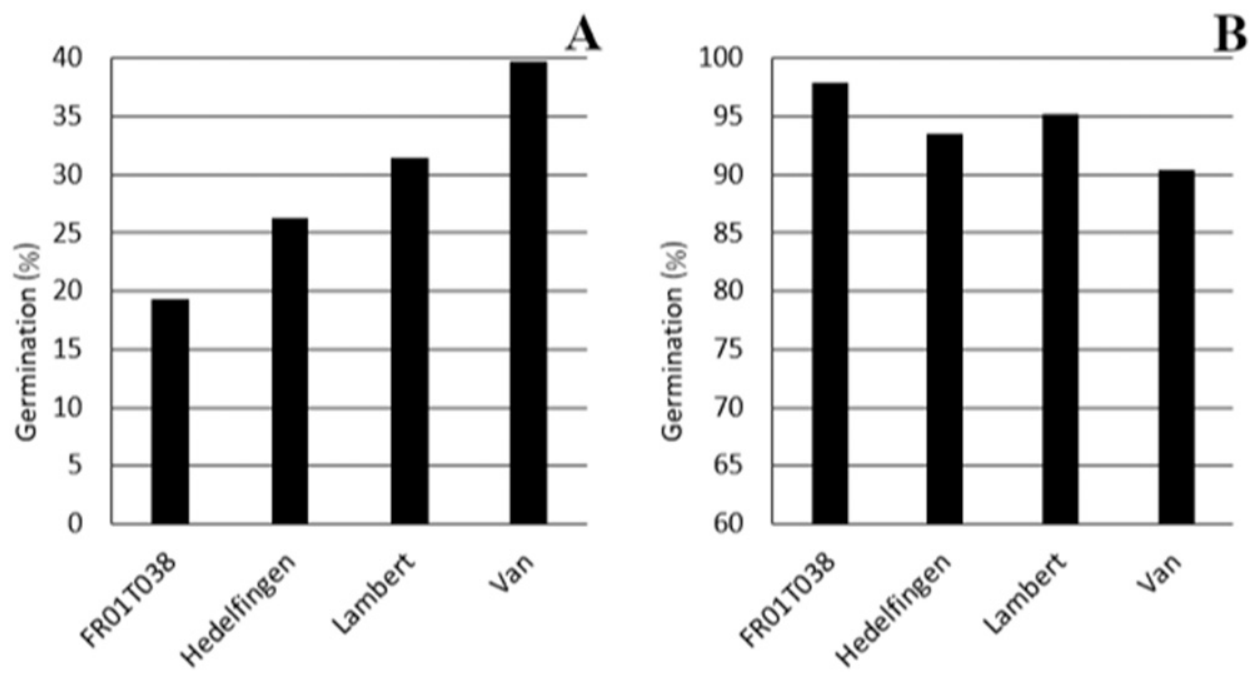

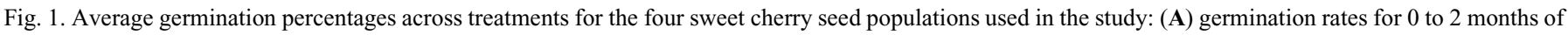
stratification and (B) germination rates after 3 and 4 months of stratification.

higher than $10 \mathrm{mg} \cdot \mathrm{L}^{-1}$ failed to produce normal seedlings following germination. Khan (1971) hypothesized that cytokinins such as kinetin interacted with gibberellins to overcome inhibitive hormones, but they would not promote germinations by themselves.

Although hydrogen peroxide, ACC, and ethephon successfully increased early germination rates, temperature had a crucial role in achieving high levels of germination. The relationship between increased stratification lengths and seed germination has been extensively observed in the stone fruits (Frisby and Seeley, 1993a; Garcia-Gusano et al., 2004). Only plants that had been chilled achieved a germination rate more than $20 \%$, and germination rates consistently increased as the stratification length increased (Table 3, Fig. 2). Like the seedcoat, the embryo and endosperm contain significant amounts of ABA (Piaggesi et al., 1991). The seedcoat of stone fruits can be largely impermeable, meaning that water and the dissolved treatments can have issues reaching the internal parts of the seed. Therefore, embryonic ABA could have had a major role in maintaining endodormancy until it significantly degraded through the standard stratification practice. Rapid warming of the seeds following their removal from cold stratification also significantly increased germination rates (Fig. 2). This rapid warming following stratification has been shown to effectively increase germination rates of other stone fruit (Garcia-Gusano et al., 2004). By transferring seeds to warmer temperatures after stratification, we could achieve germination rates higher than $90 \%$. This germination occurred several weeks earlier than it did with the current method, which involves leaving the seeds in the cold chamber until they have germinated.

Different populations germinated at differing percentages before full stratification requirements were met. Of the three commercial cultivars used in this study, Van had the highest germination percentage from 0 to 2 months of stratification, followed by Lambert and Hedelfingen (Fig. 1). It is significant to note that this corresponds to the bloom and harvest timing of these cultivars, with Van being the earliest cultivar to flower and Hedelfingen being the latest (Oregon State University, 2013). Stone fruit have been shown to require a longer strat-

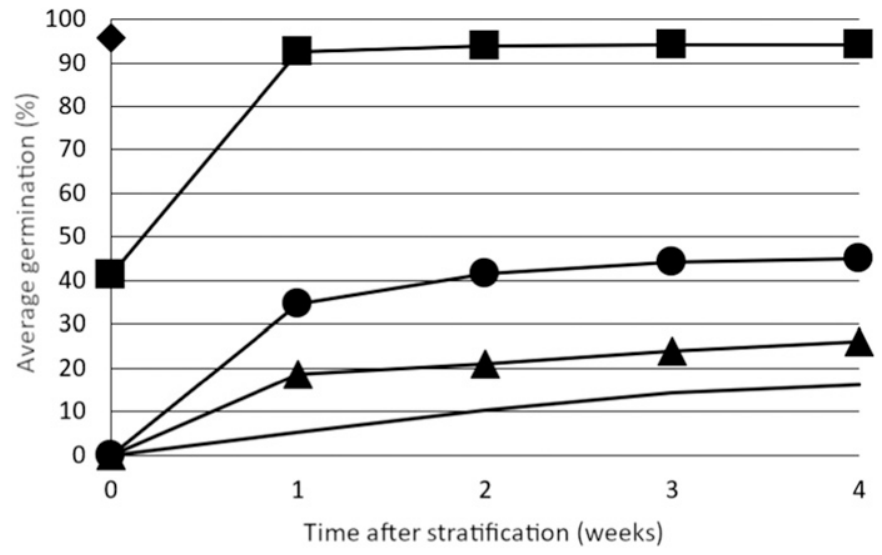

Stratification time (months) $-0 \multimap-1-2-2 \rightarrow-3-4$

Fig. 2. Effect of stratification length on sweet cherry germination percentage. The numbers of germinated seeds were recorded weekly for 4 weeks, beginning with the transfer of seeds from stratification to the growth chamber.

ification period for seed germination if the parents are laterflowering (Frisby and Seeley, 1993c; Garcia-Gusano et al., 2009; Pérez-González, 1990). Therefore, it is possible that earlierflowering cultivars also require fewer stratification hours for their seeds to germinate. A relationship among the physiological methods relating to breaking seed dormancy and bud dormancy has been suggested (Garcia-Gusano et al., 2004). Bud endodormancy, like seed endodormancy, is controlled by ABA, and similar gene pathways control dormancy for buds and seeds (Wang et al., 2016). Attempts to lengthen the sweet cherry growing season are leading to the attempted development of both earlier-ripening and later-ripening cultivars. If the correlations among flowering time, maturity time, and seed dormancy are especially strong, then they will affect how seeds are stratified. Earlier-ripening cherries should be more closely watched for high levels of early germination, and external hormonal and chemical treatments may become necessary for later-ripening cultivars to avoid long stratification periods. 

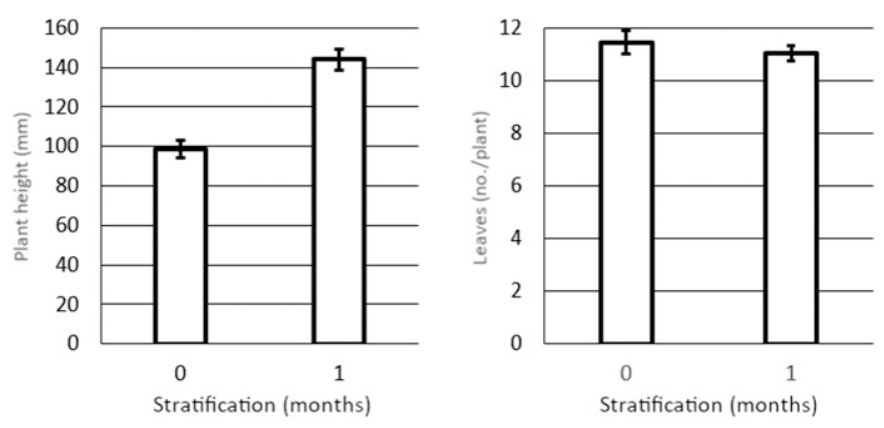

Fig. 3. Plant height and leaf number of sweet cherry seedlings grown for 2 to 3 months after 0 to 1 month of stratification. Error bars represent the sE for each stratification period.

Plants grown from seeds that were not stratified were significantly shorter than plants grown from seeds with 1 month of stratification (Fig. 3). This result has been noted extensively in other stone fruits, particularly peach (Prunus persica) (Frisby and Seeley, 1993b; Leida et al., 2012; Martinez-Gomez and Dicenta, 2001; Wang et al., 2016). We found that although plant heights were significantly greater when seeds had been stratified, the numbers of leaves were not significantly different (Fig. 3 ). This supports the findings of Martinez-Gomez and Dicenta (2001), who reported that leaf rosetting, a lack of sufficient internode growth or expansion, is the cause of reduced plant heights. This dwarfism is possibly caused by ABA located in the embryo without the chance to degrade with traditional stratification, thus leading to a type of secondary dormancy. Such rosetting has been reduced in sweet and black cherry (Prunus serotina) by foliar applications of GA (Farmer and Hall, 1971; Fogle and McCrory, 1960).

Overall, we successfully significantly increased seed germination levels to the point at which nearly $50 \%$ of seeds germinated following only 2 months of stratification. We have found that the majority of germinations occur within 1 week of removal from stratification; therefore, an objective of future studies could involve studying the feasibility of adopting a temperature-cycling program that involves keeping seeds under stratification for 2 months, warming them for 1 week to allow early seeds to germinate, and then placing them under stratification again to allow the remaining seeds to reach stratification requirements. In the future, growing test seedlings stratified for 2 months will be an important next step to ensure that there will be no secondary dormancy issues that would prevent the trees from growing to their full potential during the first year. It would also be worthwhile to test additional hormones such as GA (and other gibberellins), alternative NO sources, and combinations of ethylene precursors and ROS/RNS.

\section{Literature Cited}

Bulard, C. 1985. Intervention by gibberellin and cytokinin in the release of apple embryos from dormancy: A reappraisal. New Phytol. 101:241-249, doi: 10.1111/j.1469-8137.1985.tb02831.x.

Cetinbas, M. and F. Koyuncu. 2006. Improving germination of Prunus avium L. seeds by gibberellic acid, potassium nitrate and thiourea. Hort. Sci. (Prague) 33:119-123, doi: 10.17221/3750-HORTSCI.

Chen, S., C. Chien, J. Chung, Y. Yang, and S. Kuo. 2007. Dormancybreak and germination in seeds of Prunus campanulata (Rosaceae):
Role of covering layers and changes in concentration of abscisic acid and gibberellins. Seed Sci. Res. 17:21-32, doi: 10.1017/ S0960258507383190.

El-Maarouf-Bouteau, H. and C. Bailly. 2008. Oxidative signaling in seed germination and dormancy. Plant Signal. Behav. 3:175-182, doi: $10.4161 /$ psb.3.3.5539.

Farmer, R. and G. Hall. 1971. Gibberellic acid induces germination and growth of dormant black cherry seed. Tree Planters' Notes 22:26-28.

Finkelstein, R., W. Reeves, T. Ariizumi, and C. Steber. 2008. Molecular aspects of seed dormancy. Ann. Rev. Plant Biol 59:387-415, doi: 10.1146/annurev.arplant.59.032607.092740.

Fogle, H. and C. McCrory. 1960. Effects of cracking, after-ripening, and gibberellin on germination of 'Lambert' cherry seeds. Proc. Amer. Soc. Hort. Sci. 76:134-138.

Frisby, J. and S. Seeley. 1993a. Chilling of endodormant peach propagules: I. Seed germination and emergence. J. Amer. Soc. Hort. Sci. 118:248-252, doi: 10.21273/JASHS.118.2.248.

Frisby, J. and S. Seeley. 1993b. Chilling of endodormant peach propagules: II. Initial seedling growth. J. Amer. Soc. Hort. Sci. 118:253-257, doi: 10.21273/JASHS.118.2.253.

Frisby, J. and S. Seeley. 1993c. Chilling of endodormant peach propagules: V. Comparisons between seeds, seedlings, and cuttings. J. Amer. Soc. Hort. Sci. 118:269-273, doi: 10.21273/JASHS.118.2.269. Garcia-Gusano, M., P. Martinez-Gomez, and F. Dicenta. 2004. Breaking seed dormancy in almond [Prunus dulcis (Mill.) D.A. Webb]. Scientia Hort. 99:363-370, doi: 10.1016/j.scienta.2003.07.001.

Garcia-Gusano, M., P. Martinez-Gomez, and F. Dicenta. 2009. Chilling requirements of almond seeds related to flowering time of pollen donor. Seed Sci. Technol. 37:25-32, doi: 10.15258/sst.2009.37.1.04. Ghassemian, M., E. Nambara, S. Cutler, H. Kawaide, Y. Kamiya, and P. McCourt. 2000. Regulation of abscisic acid signaling by the ethylene response pathway in Arabidopsis. Plant Cell 12:1117-1126, doi: $10.1105 /$ tpc.12.7.1117.

Gniazdowska, A., U. Krasuska, and R. Bogatek. 2010a. Dormancy removal in apple embryos by nitric oxide or cyanide involves modifications in ethylene biosynthetic pathway. Planta 232:13971407, doi: 10.1007/s00425-010-1262-2.

Gniazdowska, A., U. Krasuska, K. Czajkowska, and R. Bogatek. 2010 b. Nitric oxide, hydrogen cyanide and ethylene are required in the control of germination and undisturbed development of young apple seedlings. Plant Growth Regulat. 61:75-84, doi: 10.1007/s10725-010-9452-2.

Javanmard, T., Z. Zamani, R. Keshavarz Afshar, M. Hashemi, and P. Struik. 2014. Seed washing, exogenous application of gibberellic acid, and cold stratification enhance the germination of sweet cherry (Prunus avium L.) seed. J. Hort. Sci. Biotechnol. 89:74-78, doi: 10.1080/14620316.2014.11513051.

Kermode, A. 2005. Role of abscisic acid in seed dormancy. J. Plant Growth Regul. 24:319-344, doi: 10.1007/s00344-005-0110-2.

Khan, A. 1971. Cytokinins: Permissive role in seed germination. Science 171(3974):853-859, doi: 10.1126/science.171.3974.853.

Kim, D. 2019. Practical methods for rapid seed germination from seed coat-imposed dormancy of Prunus yedoensis. Scientia Hort. 243:451-456, doi: 10.1016/j.scienta.2018.08.039.

Krazuska, U. and A. Gniazdowska. 2012. Nitric oxide and hydrogen cyanide as regulating factors of enzymatic antioxidant system in germinating apple embryos. Acta Physiol. Plant. 34:683-692, doi: 10.1007/s11738-011-0868-8.

Leida, C., A. Conejero, V. Arbona, A. Gomez-Cadenas, G. Llacer, M. Badenes, and G. Rios. 2012. Chilling-dependent release of seed and bud dormancy in peach associates to common changes in gene expression. PLoS One 7:e5777, doi: 10.1371/journal.pone.0035777. Liu, Y., N. Ye, R. Liu, M. Chen, and J. Zhang. 2010. $\mathrm{H}_{2} \mathrm{O}_{2}$ mediates the regulation of ABA catabolism and GA biosynthesis in Arabidopsis seed dormancy and germination. J. Expt. Bot. 60:2979-2990, doi: $10.1093 / \mathrm{jxb} / \mathrm{erq} 125$.

Martinez-Gomez, P. and F. Dicenta. 2001. Mechanisms of dormancy in seeds of peach [Prunus persica (L.) Batsch] cv. GF305. Scientia Hort. 91:51-58, doi: 10.1016/S0304-4238(01)00235-7. 
Miller, C., F. Skoog, M. Von Saltza, and F. Strong. 1955. Kinetin, a cell division factor from deoxyribonucleic acid. J. Amer. Soc. Chem. 77:1392, doi: 10.1021/ja01610a105.

Oracz, K., H. El-Maarouf-Bouteau, I. Kranner, R. Bogatek, F. Corbineau, and C. Bailly. 2009. The mechanisms involved in seed dormancy alleviation by hydrogen cyanide unravel the role of reactive oxygen species as key factors of cellular signaling during germination. Plant Physiol. 150:494-505, doi: 10.1104/pp.109.138107.

Oregon State University. 2013. Sweet cherry compatibility and bloom timing chart. 9 Feb. 2020. <https://extension.oregonstate.edu/cropproduction/fruit-trees/sweet-cherry-compatibility-bloom-timingchart>.

Pérez-González, S. 1990. Relationship between parental blossom season and speed of seed germination in peach. HortScience 25:958-960, doi: 10.21273/HORTSCI.25.8.958.
Piaggesi, A., P. Perata, C. Vitagliano, and A. Apli. 1991. Level of abscisic acid in integuments, nucellus, endosperm, and embryo of peach seeds (Prunus persica L. cv Springcrest) during development. Plant Physiol. 97:793-797, doi: 10.1104/pp.97.2.793.

Selim, H., F. Ibrahim, M. Fayek, S. Sari El-Deen, and N. Gamal. 1981. Effect of different treatments on germination of 'Romi' red grape seeds. Vitis 20:115-121, doi: 10.5073/vitis.1981.20.115-121.

Sondheimer, E., D. Tzou, and E. Galson. 1968. Abscisic acid levels and seed dormancy. Plant Physiol. 43:1443-1447, doi: 10.1007/ s00344-005-0110-2.

Wang, D., Z. Gao, P. Du, W. Xiao, Q. Tan, X. Chen, L. Li, and D. Gao. 2016. Expression of ABA metabolism-related genes suggests similarities and differences between seed dormancy and bud dormancy of peach (Prunus persica). Front. Plant Sci. 6(1248):1-17, doi: 10.3389/ fpls.2015.01248. 